\title{
PLANNING FOR CHANGE
}

\section{Assessing the Potential Role of Marine Protected Areas and Fisheries Management Approaches for Resilience Management in a Changing Ocean}

By Kristy J. Kroeker, Mark H. Carr, Peter T. Raimondi, Jennifer E. Caselle, Libe Washburn, Stephen R. Palumbi, John A. Barth, Francis Chan, Bruce A. Menge, Kristen Milligan, Mark Novak, and J. Wilson White

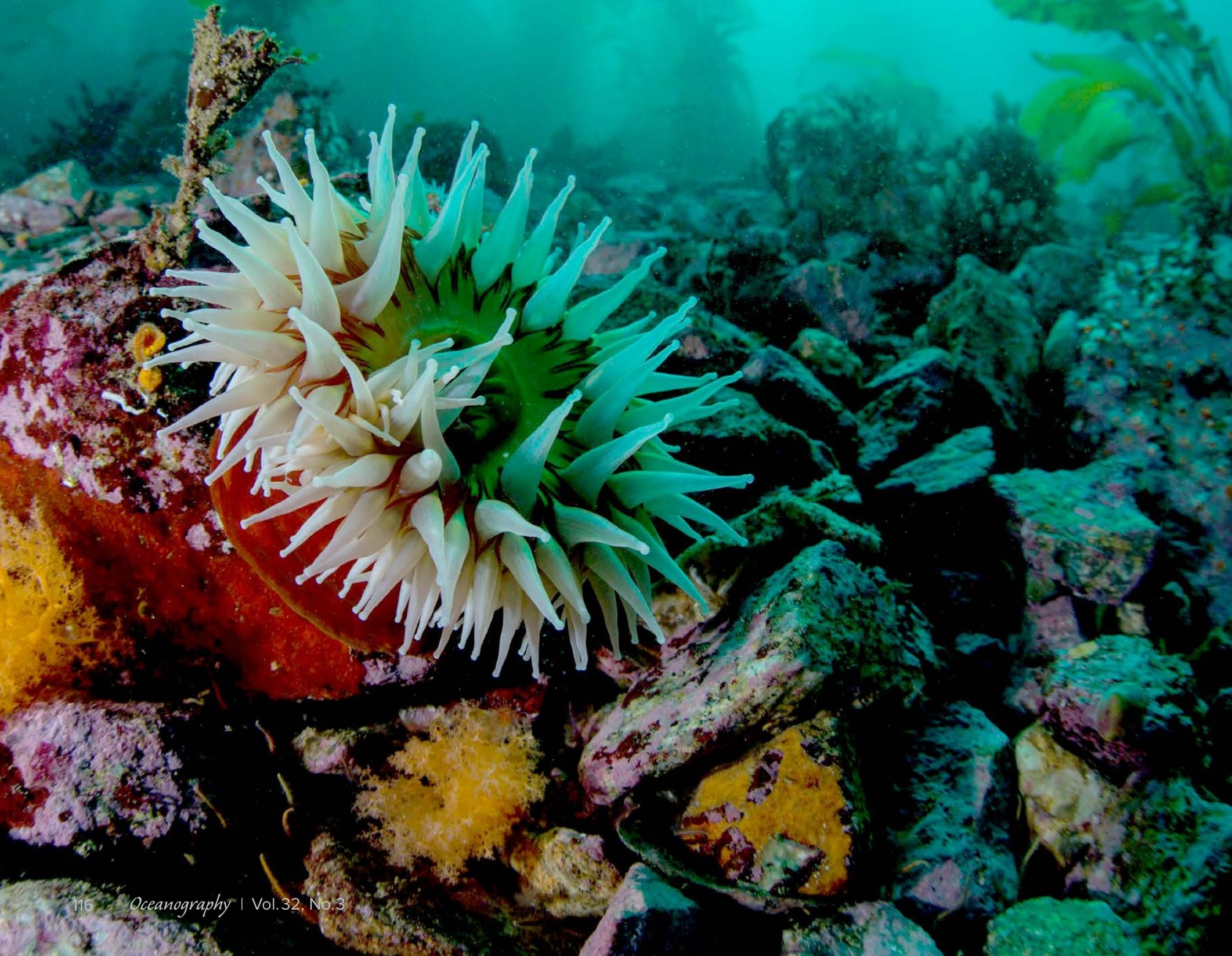


ABSTRACT. Despite progressive policies and continued advances in ocean management, numerous shifts associated with global changes have been observed in marine ecosystems in recent years, including warming, ocean acidification, and deoxygenation. As global change accelerates, science is needed to inform evidence-based management strategies for continued ecosystem services. Resilience management, in which actions are undertaken to promote the resistance and recovery responses of populations and ecosystems to disturbance, has been suggested as a possible strategy. However, empirical evidence for effective resilience management is still limited. To inform effective management strategies, mechanisms that underlie resilience to global change that can be influenced by management-ready actions must be identified and tested through observations, experiments, and modeling. Here, we discuss the potential links between three common management strategies (i.e., spatial restrictions such as marine protected areas, coordinated spatial protections, and fisheries management approaches) and potential mechanisms of resilience for marine populations and ecosystems, and provide guidance for future research on resilience management for a changing ocean drawing on insight gained by the Partnership for Interdisciplinary Studies of Coastal Oceans' work at the science-policy interface in the California Current Large Marine Ecosystem.

\section{INTRODUCTION}

Continued progress in fisheries management and a growing commitment to ecosystem-based management have led to recent numerous policy, management, and conservation successes. Fish stocks have rebounded after near total collapses due to progressive fisheries management (Thompson et al., 2017), and the number of marine protected areas (MPAs) has increased steadily across the world ocean (Boonzaier and Pauly, 2016). However, it is unlikely that current management strategies are robust enough to produce continued successes in the rapidly changing ocean that is threatened by warming, storms, sea level rise, ocean acidification, and deoxygenation. Large-scale, sometimes unpredicted, shifts in marine ecosystems are already occurring, and this trend appears to be accelerating despite the advances in fisheries management and protection. For example, large tracts of the Great Barrier Reef have bleached in recent years, including significant areas of the reef that are under protection and strict enforcement (T. Hughes et al., 2017). Similarly, in temperate oceans, the structures of many kelp forests have shifted as water temperatures have increased (Wernberg et al., 2016). Additionally, the recent collapse of the cod fishery in the Gulf of Maine, despite aggressive management of the stock
(Pershing et al., 2015), is just one example of the impacts of climate change on managed fisheries (Brander, 2010). These changes in the world's marine ecosystems suggest that new, adaptive management and science-based policies are needed to sustain the ecosystem services we rely on.

In concert with these changes, marine scientists increasingly recognize the need to shift efforts from problem identification toward strategy development. While climate change, including deoxygenation and ocean acidification, are occurring globally, most management actions are undertaken at local and regional scales. Near-term regional and local adaptation efforts are likely to rely on existing management tools that primarily involve setting limits on harvesting, local pollution, and other direct human pressures. Resilience management, that is, promoting factors that increase the resistance of an organism, population, or ecosystem to disturbances, as well as those that increase the rate of recovery to its predisturbance state (see Box 1), has emerged as a potential approach that can leverage existing management tools or inform the development of new tools at local or regional scales. Although resilience management has gained the most traction in tropical coral reef ecosystems (T. Hughes et al., 2010; Mumby et al., 2014; Anthony et al., 2015; Bruno et al., 2019), the rapid changes happening globally suggest that a broader discussion of its application in temperate and other nearshore ecosystems is warranted.

Empirical evidence for ecological resilience to climate change and ocean acidification in functioning ecosystems requires substantial long-term monitoring that can detect human-driven changes and resolve adaptational responses. Mechanisms underlying resilience, however, have been the focus of numerous studies through theory and lab-based systems (Yachi and Loreau, 1999). To move resilience from an ecological concept in science to a set of evidence-based management tools for marine ecosystems, we argue that we must first (1) identify tractable management actions affecting factors demonstrated to promote resilience, and (2) test and document the effectiveness of these resilience mechanisms to relevant global change drivers at the appropriate scales. These pieces of information are critically needed for resilience management to be a viable option for sciencemanagement partnerships.

If empirical evidence for mechanisms of resilience to global change is obtained, scientists can then identify potential geographic patterns of resilience, as well as which species and processes of coastal marine ecosystems are likely to be the most and least resilient to global change. This knowledge will facilitate analyses that map the overlap between ocean changes and the mechanisms conferring resilience, and will identify how management interventions can affect various facets of resilience across different locations. Moreover, a better understanding of resilience mechanisms may permit the development of new management tools. From this body of knowledge, managers will have evidence-informed guidance on what near- and long-term management actions can be prioritized to enhance ecological resilience in real-world systems.

Here, we discuss the demonstrated effects of three of the most common management approaches for marine ecosystems to address decision-maker-inspired 
Resilience has many definitions. An early one, related to concepts in the engineering literature, was introduced to ecologists in the 1970s as "a measure of persistence of systems and of their ability to absorb change and disturbance and still maintain the same relationships between populations or state variables" (Holling, 1973). Resilience was differentiated from stability, which was defined as "the ability of a system to return to an equilibrium state after a temporary disturbance." As early as the 1980s, scientists began considering resilience to include socialecological systems and management (Gibbs, 2009). Most broadly, the Intergovernmental Panel on Climate Change defines resilience as "the ability of a social or ecological system to absorb disturbances while retaining the same basic structure and ways of functioning, the capacity of self-organization, and the capacity to adapt to stress and change." Ecologists, in general, are familiar with a slightly deconstructed use of the resilience concept because it includes aspects of "recovery," "resistance," and "persistence" (Grimm and Wissel, 1997; Levin and Lubchenco, 2008). For example, while biological communities that are resistant are likely to be insensitive to disturbance, communities with low resistance can still be "resilient" due to rapid recovery rates. More recently, some ecologists have included a system's "adaptive capacity" as an additional key feature of resilience that reflects "the degree to which a system can adapt to new conditions" (Bernhardt and Leslie, 2013). Here, we primarily focus on the resistance and recovery aspects of resilience.

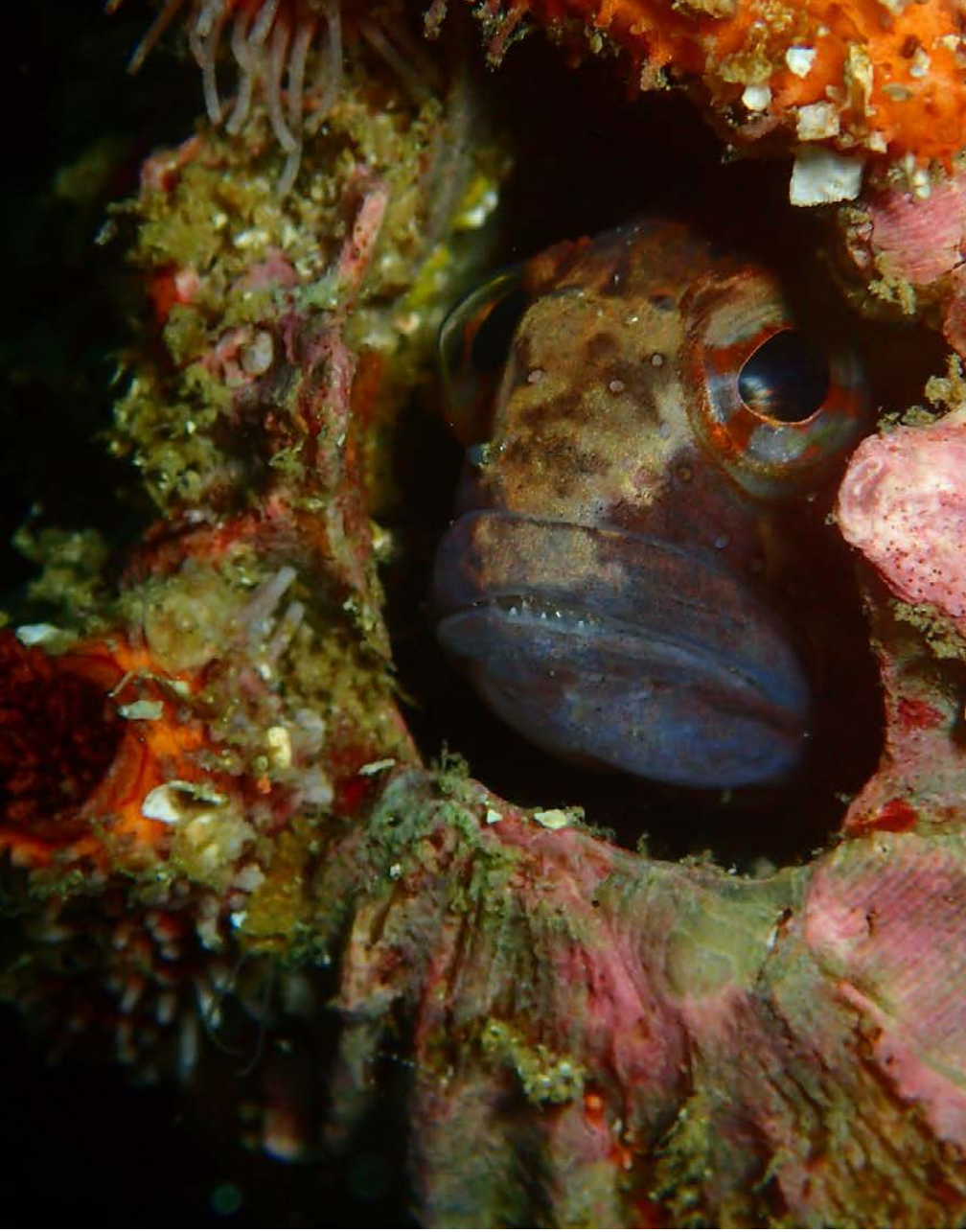

questions about opportunities for leveraging these tools for climate adaptation. They are individual-based harvest regulations (i.e., restrictions on effort and season), multi-species spatial protections from harvest/disturbance (e.g., MPAs), and coordinated spatial protections (e.g., MPA networks or other approaches to marine spatial planning). We then discuss how these management approaches align with hypothesized mechanisms of resilience (Table 1, Figure 1) and outline the research needed to assess when and where these management levers may be effective for managing ecological resilience to environmental change. Needless to say, these are not the only tools available for resilience management, nor is it clear that these tools will necessarily be effective for these means (Bates et al., 2019; Bruno et al., 2019). Instead, we use MPAs and fisheries management as examples of how to connect two disparate fields of research: observation- and modeling-based research on management interventions and theoretical work on resilience. In this regard, Table 1 is not meant to be exhaustive, but instead illustrative of potential resilience management strategies. In addition, we primarily focus on examples from the California Current Large Marine Ecosystem (CCLME), where the Partnership for Interdisciplinary Studies of Coastal Oceans (PISCO) long-term monitoring efforts are primed to inform experimental and modeling approaches at the intersection of regional, ecosystem-based management, fisheries management, and climate adaptation. We primarily address resilience to three major environmental change drivers: warming, deoxygenation, and ocean acidification.

\section{MPAS AS A RESILIENCE TOOL FOR CLIMATE ADAPTATION}

Over the last 30 years, MPAs have emerged as a critical tool for ecosystem-based management in the coastal ocean, and interest in understanding how they can be used in resilience management for global change is increasing (Bernhardt and Leslie, 2013;
Chan et al., 2016; C. Roberts et al., 2017). However, empirical evidence for a relationship between spatial protection from harvest/human disturbance and resistance to global change remains limited (but see Ling and Johnson, 2012; Micheli et al., 2012; Bates et al., 2014; Mellin et al., 2016; Caselle et al., 2018). In part, this is due to challenges associated with having adequate monitoring to quantify ecological effects of climatic and oceanographic change at appropriate temporal and spatial scales. Thus, a critical first step for informing resilience management should include careful consideration of whether or not readily demonstrable effects of MPAs on populations and ecosystem attributes may serve as effective mechanisms of resistance (Carr et al., 2018). Resilience at the ecosystem level is supported by resilience at the organismal and population levels (Box 2). Thus, management actions focused on these different levels will support resilience in ecosystem services.

A fundamental effect of spatially explicit protection from harvesting/ 
human uses is promotion of larger populations of targeted species, and sometimes, non-targeted species (Lester et al., 2009). Larger populations are less at risk of local extinction and generally have larger stores of genetic variation. Increased genetic diversity enhances the likelihood of adaptive capacity, including plasticity to environmental change (Kelly, 2019). For sessile species, more dense populations may have more effective fertilization, producing more offspring. Theory suggests that larger populations increase the probability of more resistant genotypes already existing in the population and also increase the probability that offspring will be exported to other populations (i.e., larval spillover).

In addition to population sizes, MPAs can increase the mean size of individuals in the populations (Lester et al., 2009; Caselle et al., 2015). If larger individuals are more resistant to a given disturbance, or if fecundity scales with body size, then
MPAs may also enhance the resistance or hasten the recovery of a population by contributing new recruits after a disturbance (Micheli et al., 2012). Because larger fish produce proportionally more eggs per unit biomass than do smaller fish (Barneche et al., 2018), the likelihood that large individuals protected from harvest can replenish future populations is promising. In addition, cohorts of large individuals can contribute to the recovery of populations inside and outside of the protected area. In this way, larger individuals could contribute not only to local resistance and recovery but also to the resilience of the metapopulation. If a species has high dispersal, however, and there is minimal local retention of larvae/ propagules, then this mechanism of resilience could be masked at the scale of the local population.

MPAs could also promote ecosystem resistance through ecological mechanisms. When MPAs increase species richness or diversity within a community (Lester et al., 2009), modeling suggests that functional redundancy can increase ecosystem resistance to disturbance. This mechanism primarily acts through complementarity and niche overlap in more species-rich assemblages. That is, if one species/function is lost due to disturbance, the probability that a second, more tolerant species with the same/similar function will compensate increases with species richness (Yachi and Loreau, 1999). Evidence of such effects have been demonstrated in some MPAs (Bates et al., 2014). In addition, intact food webs can also resist potential community shifts associated with altered species interactions or invasions/range shifts of new species (Ling et al., 2009; Ling and Johnson, 2012; Mellin et al., 2016; Caselle et al., 2018) and promote recovery from disturbances (Mumby and Hastings, 2008; Olds et al., 2012). Moreover, disrupted trophic linkages have been asso-

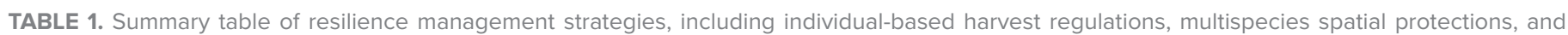

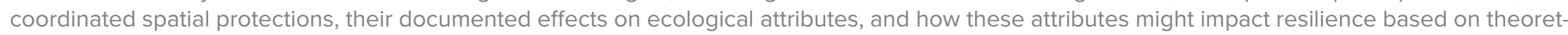

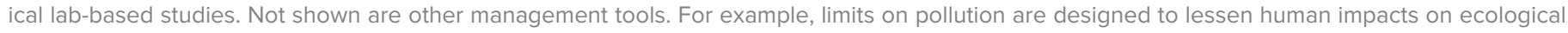
communities and confer many of the attributes identified here.

\begin{tabular}{|c|c|c|c|c|}
\hline \multicolumn{5}{|c|}{ COMMON MANAGEMENT APPROACHES } \\
\hline $\begin{array}{l}\text { Demonstrated Effect } \\
\text { of Management }\end{array}$ & $\begin{array}{l}\text { Individual- } \\
\text { Based } \\
\text { Harvest } \\
\text { Regulations }\end{array}$ & $\begin{array}{l}\text { Multispecies } \\
\text { Spatial } \\
\text { Protection }\end{array}$ & $\begin{array}{l}\text { Coordinated } \\
\text { Spatial } \\
\text { Protection } \\
\text { (e.g., MPA } \\
\text { Networks) }\end{array}$ & Hypothesized Resilience Mechanism \\
\hline $\begin{array}{l}\text { Changes in population } \\
\text { distribution }\end{array}$ & $x$ & & & $\begin{array}{l}\text { Increase resistance/recovery via refuge from environmental stress } \\
\text { in spatially or temporally variable environment }\end{array}$ \\
\hline Increased population sizes & $X$ & $X$ & & $\begin{array}{l}\text { Increase resistance via higher genetic diversity and evolutionary } \\
\text { rescue; increase recovery via higher probability of fertilization } \\
\text { success }\end{array}$ \\
\hline $\begin{array}{l}\text { Increased population age or } \\
\text { size structure }\end{array}$ & $X$ & $x$ & & $\begin{array}{l}\text { Increase resistance to environmental stress among larger } \\
\text { individuals; increase recovery via higher fecundity of larger } \\
\text { individuals }\end{array}$ \\
\hline $\begin{array}{l}\text { Maintenance of species } \\
\text { diversity }\end{array}$ & & $X$ & & Increase resistance via higher functional redundancy \\
\hline $\begin{array}{l}\text { Maintenance of trophic } \\
\text { linkages }\end{array}$ & $X$ & $X$ & & $\begin{array}{l}\text { Increase resistance to disease epidemics via suppression of } \\
\text { population outbreaks and via species interactions that prevent } \\
\text { community shifts; increase resistance to ocean acidification and } \\
\text { hypoxia via intact macrophyte communities that drawdown } \mathrm{CO}_{2} \\
\text { and produce dissolved oxygen }\end{array}$ \\
\hline $\begin{array}{l}\text { Maintenance of connectivity/ } \\
\text { habitat diversity }\end{array}$ & & & $X$ & $\begin{array}{l}\text { Increase resistance/recovery of meta-population via spatial } \\
\text { refugia of some populations from environmental stress; increase } \\
\text { resistance of species undergoing range shifts via stepping stones } \\
\text { of protection from harvest/disturbance (see other mechanisms of } \\
\text { spatial protection) }\end{array}$ \\
\hline $\begin{array}{l}\text { Maintenance of genetic/ } \\
\text { functional diversity }\end{array}$ & $X$ & $X$ & $X$ & $\begin{array}{l}\text { Increase resistance/recovery of meta-population via evolutionary } \\
\text { rescue, portfolio effect, etc. }\end{array}$ \\
\hline
\end{tabular}


ciated with disease epidemics (Lafferty, 2004), which are increasingly common in the changing ocean (Harvell et al., 2019).

Hypothetically, the reduction of local stressors other than fishing or harvest could cause the organisms within MPAs to be more resistant to the effects of global change (Krumhansl et al., 2016). For example, land-based pollution or nutrient subsidies can increase the vulnerability of coral species to thermally induced bleaching (Carilli et al., 2010), and ocean acidification can increase the toxicity of heavy metals (D. Roberts et al., 2012). Thus, limiting pollution and nutrient subsidies could promote organismal resistance. At higher levels of organization, nutrient subsidies or pollution could also exacerbate potential community shifts caused by global change if the global and local stressors push the community or ecosystem in the same direc- tion. For example, nutrient subsidies could hasten community shifts driven by species range shifts if the species/ taxa in question are also promoted by eutrophication.

There is also interest in understanding if MPAs could mitigate the chemical changes associated with ocean acidification and hypoxia at a local scale via protection of species that mediate biogeochemistry. While it is clear that macrophyte-dominated communities, such as seagrass meadows or kelp forests, can draw down $\mathrm{CO}_{2}$ locally through photosynthesis (Hendriks et al., 2014; Koweek et al., 2017), more empirical evidence is needed to assess how local these effects are, whether the changes in chemistry are ecologically relevant, and if they can contribute resistance to the ecosystem. These beneficial effects are likely to be most evident when MPAs protect macrophytes from harvest or disturbance, but can occur indirectly when MPAs protect species that contribute to their persistence (e.g., Ling et al., 2009; Ling and Johnson, 2012). Beyond their potential role in mediating chemistry, macrophytes also serve as essential nursery and adult habitats for finfish and shellfish species. Such habitats can promote resilience by enhancing survivorship through crucial juvenile life stages and supporting larger and more viable populations.

In regions where environmental change will be spatially variable, coordinated MPA networks can promote both population and ecosystem resistance and recovery by providing refugia from climatic or oceanic disturbances and opportunities for populations in unimpacted locations to contribute to the recovery of the metapopulation (Allison et al., 2003; Game et al., 2008). Even within a single

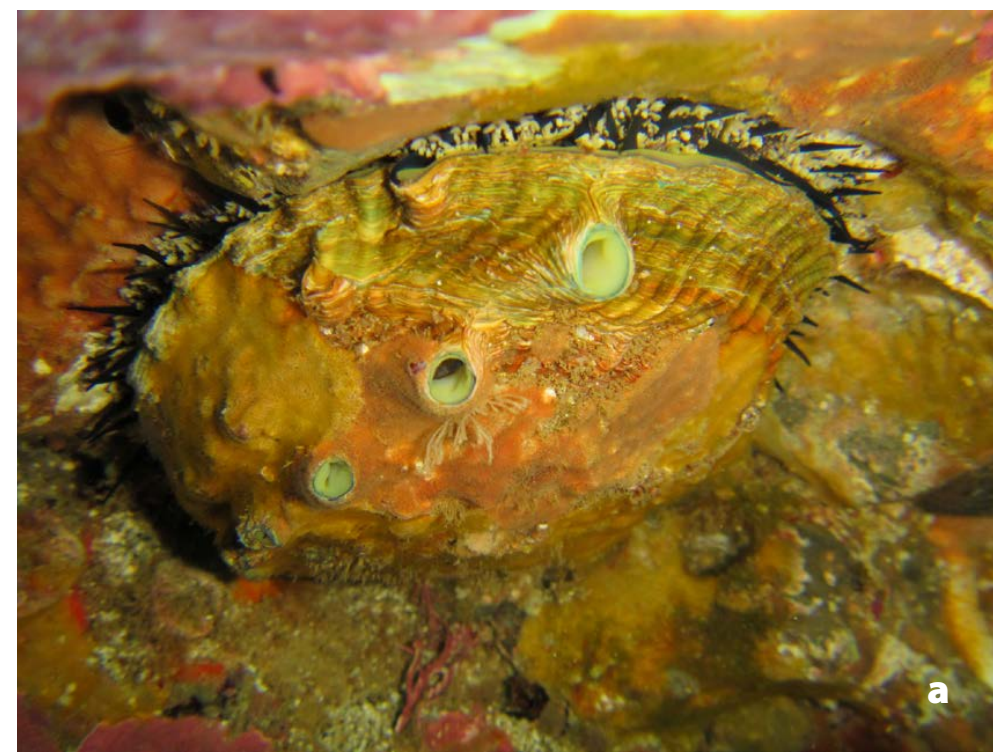

FIGURE 1. Mechanisms for resilience to global change that can be influenced by management actions can arise at (a) organismal, (b) population, and (c) ecosystem levels. For example, Micheli et al. (2012) demonstrated that at the organismal scale, (a) larger abalone in marine protected areas were more likely to survive hypoxic events. Standing genetic variation, which increases with population size, can provide population-level resistance to ocean acidification, as demonstrated among (b) purple sea urchin larvae (Pespeni et al., 2013). In addition, intact food webs, such as the one characterized by Caselle et al. (2018) with (c) large California sheepshead, can provide ecosystem level resistance to invasion by indirectly supporting native competitors with the invasive species. Photos courtesy of A. Hernandez (a), M. Langhans (b), and K. Lafferty (c)
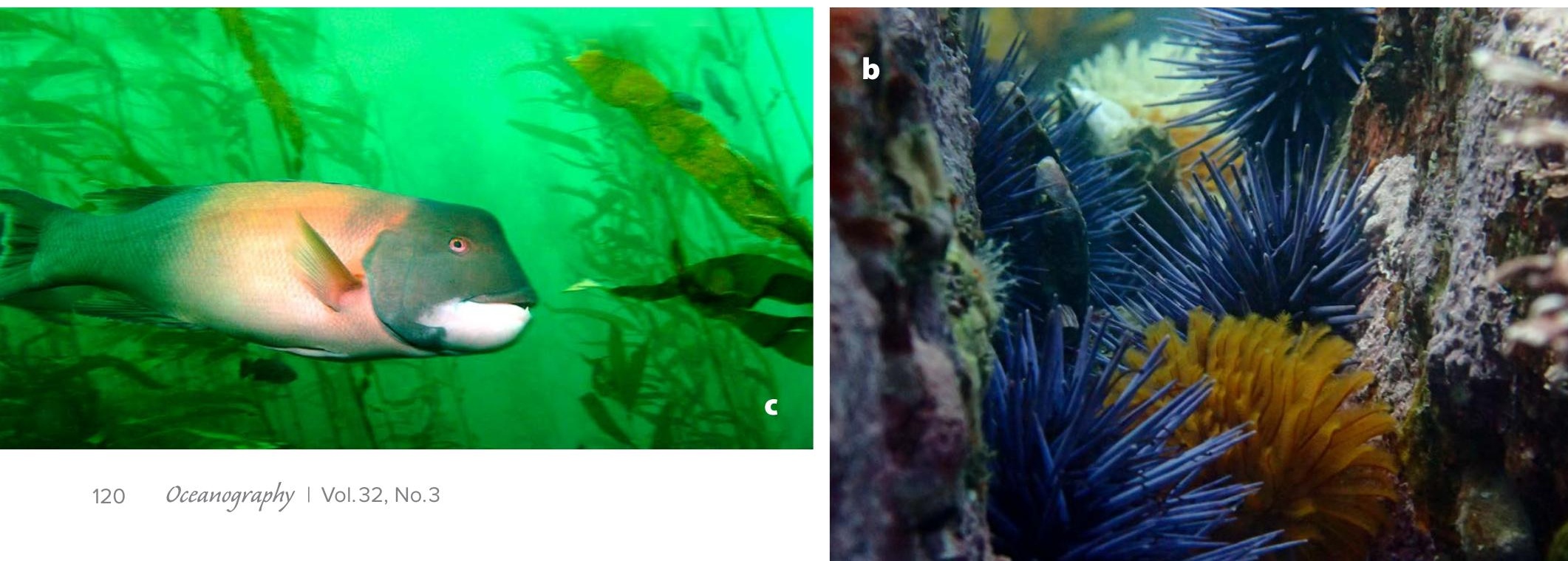
MPA, resistance and recovery can be promoted by providing refugia accessible via larval dispersal or movement of adults (e.g., depth refugia from heat waves; Carr et al., 2017). Conversely, MPAs located in regions prone to environmental extremes may protect individuals that are adapted to these conditions (Carr et al., 2017). MPA networks can also promote resistance of the metapopulation by providing stepping stones of spatial protection from human harvest/disturbance as species ranges and pelagic larval durations shift (Fox et al., 2016; Alvarez-Romero et al., 2018).

Several issues need to be addressed to effectively use MPAs for resilience. First, we need to determine under what circumstances the mechanisms of resilience discussed here actually result in increased resistance and recovery from the environmental change drivers of interest. For example, initial analyses in coral reef ecosystems suggest that MPAs can actually decrease resilience to climate extremes by favoring more thermally sensitive coral species (Bates et al., 2019; Bruno et al., 2019). Thus, species diversity (one of the resilience mechanisms discussed here) does not appear to promote communitywide resistance to thermal extremes. Once this hierarchy of understanding is developed, we also need to understand the time required for ecological attributes associated with resilience to develop inside MPAs, as well as how these features recover from disturbance. Second, we need to know when and where MPAs are most likely to experience disturbances, as well as how range shifts and altered dispersal distances will change future species distributions and local community structures. Although it may be difficult to protect populations now and also design future protections, careful consideration of potential global change-associated range shifts and changes in connectivity should be priorities in siting new MPAs and in interpreting existing MPA performance (Fox et al., 2016; Alvarez-Romero et al., 2018). Additionally, existing MPAs are very likely to require adaptive man-

\section{BOX 2. MECHANISMS OF RESILIENCE ACROSS BIOLOGICAL SCALES}

ORGANISMAL RESILIENCE to environmental change is often a function of an organism's resistance responses that maintain adequate physiological homeostasis for survival despite changing environments. For example, resistance can derive from shifts in individual physiology, behavior, or even morphology that allow an organism to acclimate to variable environments. Physiological strategies can derive from shifts in gene expression or protein function. Behavioral strategies include altering foraging patterns, habitat associations, movement, and spawning locations as a function of shifting conditions. Some individual attributes, such as body size, can promote resistance. For example, large size can confer resistance to thermal stress in the intertidal (through increased evaporative cooling) or to temporary starvation, but might enhance susceptibility to other stressors (e.g., hypoxia or wave forces).

POPULATION RESILIENCE includes the ability of a population to recover from disturbances (loss of individuals), which is a function of the rate of recolonization (i.e., recruitment) and the growth of remaining and newly colonized individuals. In marine systems, these processes are influenced by characteristics such as population size, size/age at reproductive maturity, the density dependence of growth, reproductive output, the amount of adaptive genetic diversity, and dispersal and gene flow from other habitats. For many marine species, survival and transport of propagules from other populations is particularly important. This mechanism of resilience is akin to the "rescue effect" of classic metapopulations that characterize the spatial population structure of most marine organisms. A high abundance of propagules of many marine species may allow a single-generation type of "lottery" adaptation in which recruits with adaptive genes are filtered by local conditions to provide populations of higher local fitness (see Palumbi et al., 2019, in this issue). As a result, recovered populations may have higher resistance to the same environmental perturbation. By encompassing a range of physiological tolerances to environmental variability among individuals, and by providing both shortand long-term capacity to acclimate, phenotypic variation can stabilize organism fitness and offer population-level resistance

Finally, ECOSYSTEM RESILIENCE reflects the persistence of ecosystem function and services in the face of perturbations. Ecosystem-level resistance to global change can range from organismal traits or population and community attributes that limit sensitivity to stressors (e.g., the presence of heat-tolerant genotypes or taxa and functional redundancy) or compensatory dynamics among species. Resistance can also arise from system attributes that dampen or obscure the downscaled propagation of global change stressors. Examples of such attributes include the physical barriers, such as sills, that limit connectivity to oceanic low oxygen waters, as well as dominance of local carbonate chemistry by phytoplankton blooms that obscure the full expression of the global ocean acidification signal. Similarly, the capacity for ecosystems to recover from perturbations will depend on the rates of population and community recovery and the extent to which ecosystem structure and function recovery lags or leads lower level rates of recovery. 
agement in response to global change. This adaptive management will require coupled monitoring of environmental change and ecological responses within MPAs (Carr et al., 2011) and consideration of populations and ecosystems outside MPAs that interact with those within MPAs (see fisheries management discussion below; Carr et al., 2017). In combination, such monitoring programs (inside and outside MPAs) can inform the function and design of MPAs as networks that are responsive to ocean changes.
(Chavez et al., 2017). Such shifts can encapsulate a range of local population responses to climate change, including linear declines in abundances and shifts in size structure (Cheung et al., 2013). For population-level responses, we also add (5) depletion of adaptive genetic diversity, (6) maintenance of adaptive diversity, or

(7) restructuring of genetic diversity to be greater between than within populations.

MPAs largely rely on one management lever (i.e., spatially defined elimination or reduction of fishing or other human

While experimental and observational work addressing resilience mechanisms linked to management actions can inform potential opportunities for climate adaptation, continued and expanded long-term monitoring will be critical for understanding how, when, and where the wide range of management interventions promote population and ecosystem resilience to global environmental change in complex, functioning ecosystems.

\section{RESILIENCE APPROACHES IN FISHERIES MANAGEMENT}

Climate change and ocean acidification are already affecting some fisheries and coastal economies (Barton et al., 2012; Barange et al., 2018), but our ability to forecast near-term effects of environmental change on globally diverse fisheries remains limited. Chavez et al. (2017) describe four scenarios for ecosystem-level responses to environmental change in the CCLME that encapsulate the range of responses potentially expected in other ecosystems: (1) no apparent change, (2) range shifts, (3) increased variability, and (4) phase shifts. Phase shifts are defined as "abrupt changes in the ecosystem as thresholds are crossed due to slow and steady or rapid changes in the biophysical and geochemical environment" pressures) to achieve different ecological objectives (e.g., increasing population sizes, size structure, diversity). In contrast, fisheries managers use a series of actions toward one goal-sustaining or maximizing long-term fisheries yields. The most commonly used tools include restrictions on access to a fishery, spatial and temporal closures (including MPAs), catch limits, gear restrictions, and limits on the composition (sizes and sex) of allowable catch. In addition, fisheries managers can exert their influence by allowing fishers to switch target species and promoting new fisheries (Pinsky and Mantua, 2014; Chavez et al., 2017). Again, understanding the links between these varied management actions and resilience mechanisms is important for informing effective resilience management.
Several resilience mechanisms at play in MPAs are applicable to fisheries management. For example, similar to MPAs, catch limits can influence a fishery's effective stock size and size and age structure. Increased stock sizes could also increase resistance to global change by increasing stocks' genetic and functional diversity (Hilborn et al., 2003). Different genotypes within or among populations might vary considerably in their ability to withstand global change drivers. Thus, selection in larval cohorts experiencing warmer, more acidic, or more hypoxic conditions might yield adults more resistant to such future changes. Although no evidence exists to date on this topic, the high variability and large population sizes of some marine species open the possibility that lottery-style adaptation on standing genetic variation may serve as a resilience mechanism (Pespeni et al., 2013). Additionally, fisheries managers can regulate fishing pressure by adjusting the sizes of each species that can be caught. Thus, as in MPA management, managers could promote fishery resilience if organismal or population-level resistance and recovery is size-dependent.

More generally, if we know that particular resilience mechanisms are at play in fisheries, better understanding of spatiotemporal variability in a population's vulnerability to both environmental stressors and predation within the fishery is likely to be useful for managers controlling fishery timing and location. The Dungeness crab example highlights how the intersection of fisheries and global change could potentially exacerbate a population's vulnerability. Dungeness crab sometimes concentrate in shallow areas to avoid the influx of hypoxic waters, thereby increasing their vulnerability to the fishery. Knowledge of such processes, and their spatial and temporal predictability, could enable managers and fishers to distribute fishing effort to avoid overexploitation and undermining of resilience.

The potential for phase shifts to novel states in response to global change is an 
especially important challenge for resilience management science, largely due to the difficulties in designing management strategies for ecosystem states yet to occur. There has been considerable interest in developing theory to detect early warning signals of such shifts, mainly related to scenarios involving increased variability (Scheffer et al., 2009). Longterm time series are critical for putting any variability into context (Holling, 1973; B. Hughes et al., 2017; E. White 2019). Models can provide significant insight based on the best available time series (Petchey et al., 2015; Dietze, 2017). Linked and iterative model-data frameworks will be key for resilience management because (1) models can reveal unexpected effects of climate variability on population dynamics, such as cyclic variability at particular timescales, (2) data can update and evaluate model performance, and (3) models provide a critical tool for forecasting environmental and ecological change to inform management responses (Boettiger and Hastings, 2013).

Unfortunately, using long-term monitoring data sets to detect ecosystem phase shifts faces two pernicious problems. First, it is only possible to detect such a shift and deduce its cause if long-term monitoring data already were being collected in that ecosystem. Second, developing indicators for tipping point detection based on data sets in which a phase shift is already known to have occurred can introduce bias, leading to false positives in future scenarios, a problem known as the "prosecutor's fallacy" (Boettiger and Hastings, 2012). Possible solutions to the first problem are unclear: should we begin collecting data in systems that we suspect may be most vulnerable to shifts, or should we focus efforts on continuing existing long-term studies? For the second problem, an initial remedy is to take care in estimating uncertainty in predictions (Boettiger and Hastings, 2012). A further solution is to pursue modeling approaches that formally embrace our structural uncertainty regarding the future dynamics of ecosystems (Getz et al., 2018). Fisheries managers are making decisions both on short and long timescales (e.g., initiating seasonal closures in response to sharp declines in stocks and also supporting the transition of particular fleets toward emerging fisheries). Longer-term management approaches can be informed by vulnerability assessments that account for uncertainty through scenarios (Mumby et al., 2011).

\section{INTEGRATING MPAs AND \\ FISHERIES MANAGEMENT}

Although MPAs were initially introduced as a tool to limit take in fisheries, the ecosystem-wide consequences for fisheries and broader biodiversity conservation became apparent secondarily (Carr et al., 2019, in this issue). As the pendulum swung toward using MPAs for ecosystem-based biodiversity conservation, their fishery applications received less attention. More recently, however, recognition of the inextricable linkages between MPAs and fisheries management in surrounding waters have elevated the perspective of MPAs and fisheries as a coupled management framework, designed to facilitate achieving both fisheries and conservation goals (Gaines et al., 2010). MPAs are not isolated from the effects of fisheries in their surrounding areas, and fisheries are influenced by the populations within MPAs. MPAs and fished areas replenish one another by exchanging larvae and, to a lesser degree, the adults of mobile species (McClanahan and Mangi, 2000). Although the consequences of high connectivity of marine populations and ecosystems for the vulnerability of populations and ecosystems within MPAs has long been recognized, that same connectivity underlies the ability of protected ecosystems within MPAs to sustain biodiversity beyond their boundaries and of well-managed fisheries to enhance the persistence of protected ecosystems.

The role of MPAs in directly informing climate-resilient fisheries management continues to evolve. MPAs could repre- sent an unfished benchmark for informing stock assessments (Wilson et al., 2010). By extension, they may prove to be critical tools for distinguishing fishery from climate impacts and their synergistic consequences (Carr et al., 2017). However, current methods do not evaluate the independence of population states inside and outside of MPAs or account for the time it takes for populations inside MPAs to recover to the unfished state following protection, which limits the use of MPAs for these purposes. Conversely, recent findings suggest that fine-scale variability in fishing effort leads to substantial differences in expectations for MPA performance (J. White et al., 2013; Nickols et al., 2019). MPA studies often use non-MPA sites as "controls," but this may be misguided due to interconnections in their dynamics. Thus, to successfully manage MPA networks for resilience in a changing ocean, and to use MPAs in support of climate resilient fisheries, we will need to develop integrated monitoring programs and management for both MPAs and fisheries.

\section{A PATH FORWARD FOR RESILIENCE MANAGEMENT SCIENCE IN THE TEMPERATE OCEAN}

While experimental and observational work addressing resilience mechanisms linked to management actions can inform potential opportunities for climate adaptation, continued and expanded longterm monitoring will be critical for understanding how, when, and where the wide range of management interventions promote population and ecosystem resilience to global environmental change in complex, functioning ecosystems. As the field progresses, studies using space-for-time substitutions to quantify the relationships between environmental drivers and ecological attributes (Helmuth et al., 2002; Chan et al., 2017) may be especially useful for elucidating resilience mechanisms to multiple environmental stressors. Complementing these approaches with models address- 
ing how both environmental change and resilience mechanisms associated with management actions vary across space and time will be crucial for considering the effects of all adaptive management strategies, including resilience management. Finally, we recognize that resilience management is embedded in coupled social-ecological systems and that interdisciplinary analyses that incorporate social science will be critical for understanding potential effectiveness of these and new strategies for climate adaptation (McClenachan et al., 2019).

\section{REFERENCES}

Allison, G.W., S.D. Gaines, J. Lubchenco, and H.P. Possingham. 2003. Ensuring persistence of marine reserves: Catastrophes require adopting an insurance factor. Ecological Applications 13:S8-S24, https://doi.org/10.1890/ 1051-0761(2003)013[0008:EPOMRC]2.0.CO;2.

Alvarez-Romero, J.G., A. Munguia-Vega, and M. Beger. 2018. Designing connected marine reserves in the face of global warming. Global Change Biology 24:e671-e691, https://doi.org/10.1111/ gcb.13989.

Anthony, K.R., P.A. Marshall, A. Abdulla, R. Beeden, C. Bergh, R. Black, C.M. Eakin, E.T. Game, M. Gooch, N.A. Graham, and others. 2015. Operationalizing resilience for adaptive coral reef management under global environmental change. Global Change Biology 21:48-61, https://doi.org/ 10.1111/gcb.12700.

Barange, M., T. Bahri, M.C.M. Beveridge, K.L. Cochrane, S. Funge-Smith, and F. Poulain, eds. 2018. Impacts of Climate Change on Fisheries and Aquaculture: Synthesis of Current Knowledge, Adaptation and Mitigation Options. Technical Paper 627, Food and Agriculture Organization of the United Nations, Rome, 654 pp.

Barneche, D.R., D. R. Robertson, C.R. White, and D.J. Marshall. 2018. Fish reproductive-energy output increases disproportionately with body size. Science 360:642-645, https://doi.org/10.1126/ science.aao6868.

Barton, A., B. Hales, G.G. Waldbusser, C. Langdon, and R.A. Feely. 2012. The Pacific oyster, Crassotrea gigas, shows negative correlation to naturally elevated carbon dioxide levels: Implications for nearterm ocean acidification effects. Limnology and Oceanography 57:698-710, https://doi.org/10.4319/ lo.2012.57.3.0698.

Bates, A.E., N.S. Barrett, R.D. Stuart-Smith, N.J. Holbrook, P.A. Thompson, and G.J. Edgar. 2014. Resilience and signatures of tropicalization in protected reef fish communities. Nature Climate Change 4:62-67, https://doi.org/10.1038/ nclimate2062.

Bates, A.E., R.S.C. Cooke, M.I. Duncan, G.J. Edgar, J.F. Bruno, L. Benedetti-Cecchi, I.M. Côté, J.S. Lefcheck, M.J. Costello, N. Barrett, and others. 2019. Climate resilience in marine protected areas and the 'Protection Paradox.' Biological Conservation 236:305-314, https://doi.org/10.1016/ j.biocon.2019.05.005.

Bernhardt, J.R., and H.M. Leslie. 2013. Resilience to climate change in coastal marine ecosystems. Annual Review of Marine Science 5:371-392, https://doi.org/10.1146/annurev-marine-121211-172411.
Boettiger, C., and A. Hastings. 2012. Quantifying limits to detection of early warning for critical transitions. Journal of the Royal Society Interface 9:2,527-2,539, https://doi.org/10.1098/ rsif.2012.0125.

Boettiger, C., and A. Hastings. 2013. From patterns to predictions. Nature 493:157-158, https://doi.org/ 10.1038/493157a.

Boonzaier, L., and D. Pauly. 2016. Marine protection targets: An updated assessment of global progress. Oryx 50:27-35, https://doi.org/10.1017/ S0030605315000848.

Brander, K. 2010. Impacts of climate change on fisheries. Journal of Marine Systems 79:389-402, https://doi.org/10.1016/j.jmarsys.2008.12.015.

Bruno, J.F., I.M. Côté and L.T. Toth. 2019. Climate change, coral loss, and the curious case of the parrotfish paradigm: Why don't marine protected areas improve reef resilience? Annual Review of Marine Science 11:307-334, https://doi.org/10.1146/ annurev-marine-010318-095300.

Carilli, J.E., R.D. Norris, B. Black, S.M. Walsh, and M. McField. 2010. Century-scale records of coral growth rates indicate that local stressors reduce coral thermal tolerance threshold. Global Change Biology 16:1,247-1,257, https://doi.org/ 10.1111/j.1365-2486.2009.02043.x.

Carr, M.H., C.B. Woodson, O.M. Cheriton, D. Malone, M.A. McManus, and P.T. Raimondi. 2011. Knowledge through partnerships: Integrating marine protected area monitoring and ocean observing systems. Frontiers in Ecology and the Environment 9:342-350, https://doi.org/10.1890/ 090096.

Carr, M.H., S.P. Robinson, C. Wahle, G. Davis, S. Kroll, S. Murray, E.J. Schumacker, and M. Williams. 2017. The central importance of ecological spatial connectivity to effective coastal marine protected areas and to meeting the challenges of climate change in the marine environment. Aquatic Conservation: Marine and Freshwater Ecosystems 27:6-29, https://doi.org/10.1002/ aqc. 2800.

Carr, M.H., K.L.C. Bell, P. Leary, H.L. Sagar, and S. Tucker. 2018. How MPAs Enhance the Resilience of Coastal Marine Ecosystems and their Services: A Supplemental Report by the Marine Protected Areas Federal Advisory Committee's Ecosystem Team to the Secretaries of US Department of Interior and Department of Commerce, $24 \mathrm{pp}$.

Carr, M.H., J.W. White, E. Saarman, J. Lubchenco, K. Milligan, and J.E. Caselle. 2019. Marine protected areas exemplify the evolution of science and policy. Oceanography 32(3):94-103, https://doi.org/ 10.5670/oceanog.2019.315.

Caselle, J.E., A. Rassweiler, S.L. Hamilton, and R.R. Warner. 2015. Recovery trajectories of kelp forest animals are rapid yet spatially variable across a network of temperate marine protected areas. Scientific Reports 5:14102, https://doi.org/10.1038/ srep14102.

Caselle, J.E., K. Davis, and L.M. Marks. 2018. Marine management affects the invasion success of a non-native species in a temperate reef system in California, USA. Ecology Letters 21:43-53, https://doi.org/10.1111/ele.12869.

Chan, F., A.B. Boehm, J.A. Barth, E.A. Chornesky, A.G. Dickson, R.A. Feely, B. Hales, T.M. Hill, G. Hofmann, D. lanson, and others. 2016. The West Coast Ocean Acidification and Hypoxia Science Panel: Major Findings, Recommendations, and Actions. California Ocean Science Trust, Oakland, CA, USA, 40 pp.

Chan, F., J.A. Barth, C.A. Blanchette, F.P. Chavez, O. Cheriton, G. Friederich, T.C. Gouhier, B. Gaylord, T.M. Hill, G.E. Hofmann, and others. 2017. Persistent spatial structuring of coastal ocean acidification in the California Current System. Scientific Reports 7:2526, https://doi.org/10.1038/ s41598-017-02777-y.

Chavez, F.P., C. Costello, D. Aseltine-Neilson, H. Doremus, J.C. Field, S.D. Gaines, M. Hall-Arber, N.J. Mantua, B. McCovey, C. Pomeroy, and others.
2017. Readying California Fisheries for Climate Change. California Ocean Science Trust, Oakland, California, USA, $70 \mathrm{pp}$.

Cheung, W.W.L., J.L. Sarmiento, J. Dunne, T.L. Frölicher, V.W.Y. Lam, M.L.D. Palomares, R. Watson, and D. Pauly. 2013. Shrinking of fishes exacerbates impacts of global ocean changes on marine ecosystems. Nature Climate Change 3:254-258, https://doi.org/10.1038/ nclimate1691.

Dietze, M.C. 2017. Prediction in ecology: A first-principles framework. Ecological Applications 27:2,048-2,060, https://doi.org/ 10.1002/eap.1589.

Fox, A.D., L.A. Henry, D.W. Corne, and J.M. Roberts. 2016. Sensitivity of marine protected area network connectivity to atmospheric variability. Royal Society Open Science 3:160494, https://doi.org/ 10.1098/rsos.160494.

Gaines, S.D., C. White, M.H. Carr, and S.R. Palumbi. 2010. Designing marine reserve networks for both conservation and fisheries management. Proceedings of the National Academy of Sciences of the United States of America 107:18,286-18,293, https://doi.org/10.1073/pnas.0906473107.

Game, E.T., M.E. Watts, S. Wooldridge, and H.P. Possingham. 2008. Planning for persistence in marine reserves: A question of catastrophic importance. Ecological Applications 18:670-680, https://doi.org/10.1890/07-1027.1.

Getz, W.M., C.R. Marshall, C.J. Carlson, L. Giuggioli, S.J. Ryan, S.S. Romañach, C. Boettiger, S.D. Chamberlain, L. Larsen, P. D'Odorico, and D. O'Sullivan. 2018. Making ecological models adequate. Ecology Letters 21:153-166, https://doi.org/ 10.1111/ele.12893.

Gibbs, M.T. 2009. Resilience: What is it and what does it mean for policymakers? Marine Policy 33:322-331, https://doi.org/10.1016/ j.marpol.2008.08.001.

Grimm, V., and C. Wissel. 1997. Babel, or the ecological stability discussions: An inventory and analysis of terminology and a guide for avoiding confusion. Oecologia 109:323-334, https://doi.org/10.1007/ s004420050090.

Harvell, C.D., D. Montecino-Latorre, J.M. Caldwell, J.M. Burt, K. Bosley, A. Keller, S.F. Heron, A.K. Salomon, L. Lee, O. Pontier, and others. 2019. Disease epidemic and a marine heat wave are associated with the continental-scale collapse of a pivotal predator (Pycnopodia helianthoides). Science Advances 5:eaau7042, https://doi.org/ 10.1126/sciadv.aau7042.

Helmuth, B., C.D.G. Harley, P.M. Halpin, M. O'Donnell, G.E. Hofmann, and C.A. Blanchette. 2002. Climate change and latitudinal patterns of intertidal thermal stress. Science 298:1,015-1,017, https://doi.org/ 10.1126/science.1076814.

Hendriks, I.E., Y.S. Olsen, L. Ramajo, L. Basso,

A. Steckbauer, T.S. Moore, J. Howard, and C.M. Duarte. 2014. Photosynthetic activity buffers ocean acidification in seagrass meadows. Biogeosciences 11:333-346, https://doi.org/ 10.5194/bg-11-333-2014.

Hilborn, R., T.P. Quinn, D.E. Schindler, and D.E. Rogers. 2003. Biocomplexity and fisheries sustainability. Proceedings of the National Academy of Sciences of the United States of America 11:6,564-6,568, https://doi.org/10.1073/pnas.1037274100.

Holling, C.S. 1973. Resilience and stability of ecological systems. Annual Review of Ecology, Evolution, and Systematics 4:1-23, https://doi.org/10.1146/ annurev.es.04.110173.000245.

Hughes, B.B., R. Beas-Luna, A.K. Barner, K. Brewitt, D.R. Brumbaugh, E.B. Cerny-Chipman, S.L. Close, K.E. Coblentz, K.L. de Nesnera, S.T. Drobnitch, and others. 2017. Long-term studies contribute disproportionately to ecology and policy. BioScience 67:271-281, https://doi.org/10.1093/ biosci/biw185. 
Hughes, T.P., N.A.J. Graham, J.B.C. Jackson, P.J. Mumby, and R.S. Steneck. 2010. Rising to the challenge of sustaining coral reef resilience. Trends in Ecology \& Evolution 25:633-642, https://doi.org/ 10.1016/j.tree.2010.07.011.

Hughes, T.P., J.T. Kerry, M. Álvarez-Noriega, J.G. Álvarez-Romero, K.D. Anderson, A.H. Baird, R.C. Babcock, M. Beger, D.R. Bellwood, R. Berkelmans, and others. 2017. Global warming and recurrent mass bleaching of corals. Nature 543:373-377, https://doi.org/10.1038/ nature21707.

Kelly, M.W. 2019. Adaptation to climate change through genetic accommodation and assimilation of plastic phenotypes. Philosophical Transactions the Royal Society B, https://doi.org/10.1098/ rstb.2018.0176.

Koweek, D.A., K.J. Nickols, P.R. Leary, S.Y. Litvin, T.W. Bell, T. Luthin, S. Lummis, D.A. Mucciarone, and R.B. Dunbar. 2017. A year in the life of a central California kelp forest: Physical and biological insights into biogeochemical variability. Biogeosciences 14:31-44, https://doi.org/10.5194/ bg-14-31-2017.

Krumhansl, K.A., D.K. Okamoto, A. Rassweiler, M. Novak, J.J. Bolton, K.C. Cavanaugh, S.D. Connell, C.R. Johnson, B. Konar, S.D. Ling, and F. Micheli. 2016. Global patterns of kelp forest change over the past half-century. Proceedings of the National Academy of Sciences of the United States of America 113:13,785-13,790, https://doi.org/ 10.1073/pnas.1606102113.

Lafferty, K.D. 2004. Fishing for lobsters indirectly increases epidemics in sea urchins. Ecological Applications 14:1,566-1,573, https://doi.org/ 10.1890/03-5088.

Lester, S.E., B.S. Halpern, K. Grorud-Colvert, J. Lubchenco, B.I. Ruttenberg, S.D. Gaines, S. Airame, and R.R. Warner. 2009. Biological effects within no-take marine reserves: A global synthesis. Marine Ecology Progress Series 384:33-46, https://doi.org/10.3354/meps08029.

Levin, S.A., and J. Lubchenco. 2008. Resilience, robustness, and marine ecosystem-based management. BioScience 58:27-32, https://doi.org/10.1641/ B580107.

Ling, S.D., C.R. Johnson, S.D. Frusher, and K.R. Ridgway. 2009. Overfishing reduces resilience of kelp beds to climate-driven catastrophic phase shift. Proceedings of the National Academy of Sciences of the United States of America 106:22,341-22,345, https://doi.org/10.1073/ pnas.0907529106.

Ling, S.D., and C.R. Johnson. 2012. Marine reserves reduce risk of climate-driven phase shift by reinstating size- and habitat-specific trophic interactions. Ecological Applications 22:1,232-1,245, https://doi.org/10.1890/11-1587.1.

McClanahan, T.R., and S. Mangi. 2000. Spillover of exploitable fishes from a marine park and its effect on the adjacent fishery. Ecological Applications 10:1,792-1,805, https://doi.org/10.1890/ 1051-0761(2000)010[1792:SOEFFA]2.0.CO;2.

McClenachan, L., S. Scyphers, and J.H. Grabowski. 2019. Views from the dock: Warming waters, adaptation and the future of Maine's lobster fishery. Ambio 1-12, https://doi.org/10.1007/ s13280-019-01156-3.

Mellin, C., M.A. MacNeil, A.J. Cheal, M.J. Emslie, and M.J. Caley. 2016. Marine protected areas increase resilience among coral reef communities. Ecology Letters 19:629-637, https://doi.org/10.1111/ ele.12598.

Micheli, F., A. Saenz-Arroyo, A. Greenley, L. Vazquez, J.A.E. Montes, M. Rossetto, and G.A. DeLeo. 2012. Evidence that marine reserves enhance resilience to climatic impacts. PLOS ONE 7:e40832, https://doi.org/10.1371/journal.pone.0040832.

Mumby, P.J., and A. Hastings. 2008. The impact of ecosystem connectivity on coral reef resilience. Journal of Applied Ecology 45:854-862, https://doi.org/10.1111/j.1365-2664.2008.01459.x.
Mumby, P.J., I.A. Elliott, C.M. Eakin, W. Skirving, C.B. Paris, H.J. Edwards, S. Enríquez, R. IglesiasPrieto, L.M. Cherubin, and J.R. Stevens. 2011. Reserve design for uncertain responses of coral reefs to climate change. Ecology Letters 14:132-140, https://doi.org/10.1111/ j.1461-0248.2010.01562.x.

Mumby, P.J., I. Chollett, Y.-M. Bozec, and N.H. Wolff. 2014. Ecological resilience, robustness and vulnerability: How do these concepts benefit ecosystem management. Current Opinion in Environmental Sustainability 7:22-27, https://doi.org/10.1016/ j.cosust.2013.11.021.

Nickols, K.J., J.W. White, D. Malone, M.H. Carr, R.M. Starr, M.L. Baskett, A. Hastings, and L.W. Botsford. 2019. Setting ecological expectations for adaptive management of marine protected areas. Journal of Applied Ecology, https://doi.org/ 10.1111/1365-2664.13463.

Olds, A.D., K.A. Pitt, P.S. Maxwell, and R.M. Connolly. 2012. Synergistic effects of reserves and connectivity on ecological resilience. Journal of Applied Ecology 49:1,195-1,203, https://doi.org/10.1111/ jpe.12002.

Palumbi, S.R., T.G. Evans, M.H. Pespeni, and G.N. Somero. 2019. Present and future adaptation of marine species assemblages: DNA-based insights into climate change from studies of physiology, genomics, and evolution. Oceanography 32(3):82-93, https://doi.org/ 10.5670/oceanog.2019.314.

Pershing, A.J., M.A. Alexander, C.M. Hernandez, L.A. Kerr, A.L. Bris, K.E. Mills, J.A. Nye, N.R. Record, H.A. Scannell, J.D. Scott, and others. 2015. Slow adaptation in the face of rapid warming leads to collapse of the Gulf of Maine cod fishery. Science 350:809-812, https://doi.org/10.1126/ science.aac9819.

Pespeni, M.H., E. Sanford, B. Gaylord, T.M. Hill, J.D. Hosfelt, H.K. Jaris, M. LaVigne, E.A. Lenz, A.D. Russell, M.K. Young, and S.R. Palumbi. 2013. Evolutionary change during experimental ocean acidification. Proceedings of the National Academy of Sciences of the United States of America 110:6,937-6,942, https://doi.org/10.1073/ pnas.1220673110.

Petchey, O.L., M. Pontarp, T.M. Massie, S. Kefi, A. Ozgul, M. Weilenmann, G.M. Palamara, F. Altermatt, B. Matthews, J.M. Levine, and others. 2015. The ecological forecast horizon, and examples of its uses and determinants. Ecology Letters 18:597-611, https://doi.org/10.1111/ele.12443.

Pinsky, M.L., and N.J. Mantua. 2014. Emerging adaptation approaches for climate ready fisheries management. Oceanography 27(4):146-159, https://doi.org/10.5670/oceanog.2014.93.

Roberts, C.M., B.C. O'Leary, D.J. McCauley, P.M. Cury, C.M. Duarte, J. Lubchenco, D. Pauly, A. SaenzArroyo, U.R. Sumaila, R.W. Wilson, and others. 2017. Marine reserves can mitigate and promote adaptation to climate change. Proceedings of the National Academy of Sciences of the United States of America 114:6,167-6,175, https://doi.org/10.1073/ pnas.1701262114.

Roberts, D.A., S.N.R. Birchenough, C. Lewis, M.B. Sanders, T. Bolam, and D. Sheahan. 2012. Ocean acidification increases the toxicity of contaminated sediments. Global Change Biology 19:340-351, https://doi.org/10.1111/ gcb.12048.

Scheffer, M.J. Bascompte, W.A. Brock, V. Brovkin, S.R. Carpenter, V. Dakos, H. Held, E.H. van Nes, M. Rietkerk, and G. Sugihara. 2009. Early-warning signals for critical transitions. Nature 461:53-59, https://doi.org/10.1038/nature08227.

Thompson, A.R., D.C. Chen, L.W. Guo, J.R. Hyde, and W. Watson. 2017. Larval abundances of rockfishes that were historically targeted by fishing increased over 16 years in association with a large marine protected area. Royal Society Open Science 4:170639, https://doi.org/10.1098/ rsos.170639.
Wernberg, T., S. Bennett, R.C. Babcock,

T.D. Bettignies, K. Cure, M. Depczynski, F. Dufois, J. Fromont, C.J. Fulton, R.K. Hovey, and others. 2016. Climate-driven regime shift of a temperate marine ecosystem. Science 353:169-172, https://doi.org/10.1126/science.aad8745.

White, E.R. 2019. Minimum time required to detect population trends: The need for long-term monitoring programs. BioScience 69:40-46, https://doi.org/10.1093/biosci/biy144.

White, J.W., L.W. Botsford, A. Hastings, M.L. Baskett D.M. Kaplan, and L.A.K. Barnett. 2013. Transient responses of fished populations to marine reserve establishment. Conservation Letters 6:180-191, https://doi.org/10.1111/j.1755-263X.2012.00295.x.

Wilson, J.R., J.D. Prince, and H.S. Lenihan. 2010. A management strategy for sedentary nearshore species that uses marine protected areas as a reference. Marine Coastal Fisheries: Dynamics, Management, and Ecosystem Science 2:14-27, https://doi.org/10.1577/C08-0261.

Yachi, S., and M. Loreau. 1999. Biodiversity and ecosystem productivity in a fluctuating environment: The insurance hypothesis. Proceedings of the National Academy of Sciences of the United States of America 96:1,463-1,468, https://doi.org/10.1073/ pnas.96.4.1463.

\section{ACKNOWLEDGMENTS}

PISCO is supported by the David and Lucile Packard Foundation \#2017-65575. This is PISCO contribution 500

\section{AUTHORS}

Kristy J. Kroeker (kkroeker@ucsc.edu) is Associate Professor, Mark H. Carr is Professor, and Peter T. Raimondi is Professor, all in the Department of Ecology and Evolutionary Biology, University of California, Santa Cruz, CA, USA. Jennifer E. Caselle is Research Biologist, Marine Science Institute, and Libe Washburn is Professor, Department of Geography, both at the University of California, Santa Barbara, CA, USA. Stephen R. Palumbi is Professor, Department of Biology, Stanford University, Stanford, CA, USA. John A. Barth is Professor, College of Earth, Ocean, and Atmospheric Sciences, Francis Chan is Associate Professor, Department of Integrative Biology, Bruce A. Menge is Professor, Department of Integrative Biology, Kristen Milligan is PISCO Program Coordinator, Mark Novak is Associate Professor, Department of Integrative Biology, and J. Wilson White is Assistant Professor, Fisheries and Wildlife, all at Oregon State University, Corvallis, OR, USA

\section{ARTICLE CITATION}

Kroeker, K.J., M.H. Carr, P.T. Raimondi, J.E. Caselle, L. Washburn, S.R. Palumbi, J.A. Barth, F. Chan, B.A. Menge, K. Milligan, M. Novak, and J.W. White. 2019. Planning for change: Assessing the potential role of marine protected areas and fisheries management approaches for resilience management in a changing ocean. Oceanography 32(3):116-125, https://doi.org/10.5670/oceanog.2019.318.

\section{COPYRIGHT \& USAGE}

This is an open access article made available under the terms of the Creative Commons Attribution 4.0 International License (https://creativecommons.org/ licenses/by/4.0/), which permits use, sharing, adaptation, distribution, and reproduction in any medium or format as long as users cite the materials appropriately, provide a link to the Creative Commons license, and indicate the changes that were made to the original content. 